\title{
Burn injury characteristics: findings from Pakistan National Emergency Department Surveillance Study
}

\author{
Emaduddin Siddiqui ${ }^{1 *}$, Nukhba Zia', Asher Feroze ${ }^{1}$, Safia Awan², Arifa Liaquat Ali ${ }^{1}$, Junaid Abdul Razzak ${ }^{3,6}$,
} Adnan A Hyder ${ }^{4}$, Asad Latif ${ }^{4,5}$

\begin{abstract}
Background: Burn injury is an important yet under-researched area in Pakistan. The objective of this study was to determine the characteristics and associated outcomes of burn injury patients presenting to major emergency departments in Pakistan.

Methods: Pakistan National Emergency Department Surveillance (Pak-NEDS) was a pilot active surveillance conducted between November 2010 and March 2011. Information related to patient demographics, mode of arrival, cause of burn injury, and outcomes was analyzed for this paper. Data were entered using Epi Info and analyzed using SPSS v.20. Ethical approval was obtained from all participating sites.
\end{abstract}

Results: There were 403 burn injury patients in Pak-NEDS, with a male to female ratio 2:1. About $48.9 \%$ of the burn injury patients $(n=199)$ were between $10-29$ years of age. There was no statistically significant difference between unintentional and intentional burn injury patients except for body part injured ( $p$-value 0.004) and ED disposition ( $p$-value 0.025). Among 21 patients who died, most were between 40 - 49 years of age (61.9\%) and suffered from fire burns (81\%).

Conclusion: Burn injuries are a burden on emergency rooms in Pakistan. We were able to demonstrate the significant burden of burn injuries that is not addressed by specialized burn centers.

\section{Background}

Burn injuries are a global public health problem with physical, psychological, and economic implications for patients, their families, and society as a whole [1]. Around $90 \%$ of all burns injuries occur in low- and middle income countries (LMICs) [2]. Burns are the fourth leading cause of injury following road traffic injuries, falls, and interpersonal violence, accounting for $5-12 \%$ of all injuries worldwide and around 11 million patients requiring medical attention [3-5]. About 265,000 people die each year due to burn injuries according to the World Health Organization (WHO) [6]. This current burden of burn injuries is deeply inequitable, with incidence disproportionately affecting the poor and the vulnerable [7].

\footnotetext{
* Correspondence: emaduddin.siddiqui@aku.edu

'Department of Emergency Medicine, Aga Khan University, Karachi, Pakistan
} Full list of author information is available at the end of the article
Around two-thirds of burn injuries occur in the African, Eastern Mediterranean and South-East Asia regions of the WHO [8]. The annual incidence of burn injuries in the Eastern Mediterranean and South-East Asia regions is estimated to be 187 and 243 per 100,000 population, respectively [9]. Mortality rates from fire-related burns are the highest in the South-East Asia region (11.6 per 100,000 population) and when compared to the 1 death per 100,000 population found in high-income countries (HICs), this is one of the largest discrepancies for any injury mechanism [2]. The pattern of burn injury and the groups affected in LMICs and HICs also differs; for example, among the 15-59 year age group, the mortality rate due to fire-related burn injury in HICs is twice as high for males compared to females, while the reverse is true in LMICs [2].

Burn injury is an important yet under-researched area in Pakistan. The Global Burden of Disease 2010 study 
estimates that the age-standardized mortality rate for injury caused by fire, heat, and hot substances is 5.8 per 100,000 population in Pakistan [2]. A burn facility-based study from Karachi estimated burn-associated mortality rate among adults between 15 - 55 years to be even higher at 10.2 per 100,000 population [10]. Some risk factors reported to be associated with admission and mortality include female gender, age $>50$ years, fire burn, inhalational injury, and total body surface area (TBSA) of $>40 \%[11,12]$. However, most of the existing knowledge regarding burn injuries in Pakistan is from single-center studies in specialized burn hospitals found in major cities [11-15].

Existing data make it difficult to estimate the true burden of burn injuries on the general population and little is known about the epidemiology of burn injury in the population that does not present to specialized burn centers. This is an important knowledge gap as specialized burn centers are not accessible to a large portion of the Pakistani population. Emergency departments (EDs) are a logical first point of contact for care of burn injury patients. The overall aim of this study is to determine the characteristics of burn injury patients presenting to urban tertiary care EDs across Pakistan. The specific objectives of the study are to understand burns as a mechanism of injury for unintentional and intentional injuries and to look at burn injury characteristics based on patient disposition from the ED.

\section{Methods}

The Pakistan National Emergency Departments Surveillance (Pak-NEDS) was an active surveillance program conducted in seven major urban tertiary care EDs across Pakistan. Data was collected between November 2010 and March 2011 on all patients seeking care in participating EDs. Pak-NEDS enrolled 274,436 patients. The study sites consisted of two private and five public sector hospitals, each of which are considered major tertiary care centers in their respective cities. These centers included: the Aga Khan University (AKU) and Jinnah Post-graduate Medical Center in Karachi; Benazir Bhutto Hospital in Rawalpindi; Lady Reading Hospital in Peshawar; Mayo Hospital in Lahore; Sandeman Provincial Hospital in Quetta; and Shifa International Hospital in Islamabad.

A one-page standardized data collection tool was developed based on the ambulatory care survey from the Centers for Disease Control and Prevention, USA and previous surveillance conducted in Pakistan $[16,17]$. The tool was reviewed and approved by the heads of the EDs at each of the institutions involved in the study. Data were collected by dedicated data collectors hired and trained specifically for Pak-NEDS. All patients coming to the participating EDs were approached after their registration in the ED; data was gathered by interviews with patients or next of kin, from the ED physician, and by review of the patient medical record. All data were gathered while the patient was in the ED and there was no contact with the patient following discharge from the ED. Ethical approval was obtained from all participating sites in Pakistan as well as from the Institutional Review Board of the Johns Hopkins Bloomberg School of Public Health in the United States.

For the purpose of this analysis, we looked at all the patients in the Pak-NEDS dataset who presented to the ED with any form of burn injury. We analyzed information related to patient demographics (such as age, gender, and ethnicity), mode of arrival to ED, cause and intent of burn injury, and disposition from the ED. Data was entered into Epi Info version 3.3.2 by a data management team at AKU [18]. For purposes of comparison, age was categorized into seven age groups: under 5 years, 5 - 9 years, $10-19$ years, $20-29$ years, $30-39$ years, $40-49$ years, and 50 years and above. Patient disposition from the ED was categorized into: discharged home from ED; admitted to hospital for further care and management; death in ED; or 'Other,' which included left ED without being seen, left against medical advice, or referred to another facility. Data analysis was conducted using SPSS version 20 [19].

For descriptive analysis, frequencies for gender, type of hospital, mode of arrival to ED, intent of injury, and cause of injury were calculated. Due to the non-normal distribution of age in the dataset, median age and interquartile range were calculated. The intent of burn injury and three disposition categories - discharged from ED, admitted, and death in ED - were separately compared with patient demographic and burn injury characteristics using chi squared tests and Fisher Exact test. The level of significance was set at 0.05 .

\section{Results}

There were 403 burn injury patients in Pak-NEDS. This translates into 146.8 burn injury patients per 100,000 ED visits in Pakistan. Males comprised 67.2\% ( $\mathrm{n}=271$ ) of patients, outnumbering females in all age groups leading to an overall male to female ratio of 2:1 (Table 1). Nearly half of the patients $(n=199)$ were between $10-29$ years of age; a quarter of the patients were over 40 years. The median age was 25 years (interquartile range $19-38$ years). Most burn injury patients arrived to the ED via non-ambulance transport $(\mathrm{n}=331,82.13 \%)$.

The intent of the injury was known for about threequarters $(n=308)$ of burn patients and of these about $65.3 \%(n=201)$ were reported to be unintentional in nature. For about a quarter of patients $(n=107,26.5 \%)$, burns were recorded as intentional burns. The main causes of burns were scalds $(n=259,64.3 \%)$, followed by fire, flame, or smoke burns $(n=66,16.4 \%)$. The injured 
Table 1. Demographic characteristics of burn patients in Pakistan ( $n=403$ )

\begin{tabular}{lc}
\hline Demographic Characteristics & $\mathbf{n}(\%)$ \\
\hline Gender & $271(67.2)$ \\
Male & $132(32.8)$ \\
$\quad$ Female & $22(5.5)$ \\
\hline Age Group & $19(4.7)$ \\
Under 5 years & $68(16.9)$ \\
$5-9$ years & $131(32.5)$ \\
10-19 years & $66(16.4)$ \\
$20-29$ years & $59(14.6)$ \\
$30-39$ years & $38(9.4)$ \\
$40-49$ years & \\
$\geq 50$ years & $25(6.2)$ \\
\hline Mode of Transport & $331(82.13)$ \\
Ambulance & $47(11.7)$ \\
Non ambulance & \\
Not reported & $377(93.5)$ \\
\hline Hospital Type & $26(6.5)$ \\
Public Hospital &
\end{tabular}

body region was known in 320 patients (79.4\%), with extremities being the most commonly burnt $(\mathrm{n}=174$, $54.4 \%)$, followed by head, neck, and face $(\mathrm{n}=101,31.6 \%)$. Patient disposition from the ED was known for about $80 \%(\mathrm{n}=324)$ of patients; $20.1 \%(\mathrm{n}=65)$ were admitted for further care, and $6.5 \%(\mathrm{n}=21)$ died in the ED (Table 2).

The intent of burn injury was compared with patient demographic (gender, age group, mode of transportation, hospital type) and burn injury characteristics (cause of burn, body part injured, degree of burns, ED disposition). There was no statistically significant difference between unintentional burn injury patients and patients with intentional injury caused by burns except for body part injured (p-value 0.004) and ED disposition (p-value 0.025). (Table 3)

Table 4 compares patient and burn injury characteristics based on three ED disposition groups (discharged from ED, admitted, and death). A statistically significant difference was observed in all patient and burn injury characteristics between the three categories of ED disposition except for intent (p-value 0.186) and degree of burns (0.073). Patients between 20 - 29 years of age comprised the largest proportion of those discharged from the ED $(36.7 \%, \mathrm{n}=80)$ and those that were admitted $(30.8 \%, n=20)$. Out of the 21 patients who died in the ED, $61.9 \%$ were between 40 - 49 years of age. There were no deaths in children under 10 years of age. The majority of patients who were discharged home from the ED ( $\mathrm{n}=212,97.2 \%)$ or were admitted $(n=63,96.9 \%)$ presented to the EDs of public hospitals
Table 2. Burn injury characteristics in Pakistan $(n=403)$

\begin{tabular}{|c|c|}
\hline Burn Injury Characteristics & n (\%) \\
\hline \multicolumn{2}{|l|}{ Intent of injury $(n=308)$} \\
\hline Self-inflicted & $45(14.6)$ \\
\hline Assault & $62(20.1)$ \\
\hline Unintentional & 201(65.2) \\
\hline \multicolumn{2}{|l|}{ Cause Of Burn } \\
\hline Scalds & $259(64.3)$ \\
\hline Fire burns & $66(16.4)$ \\
\hline Chemical & $10(2.5)$ \\
\hline Others & $68(16.9)$ \\
\hline \multicolumn{2}{|l|}{ Body Part Injured $(n=320)$} \\
\hline Limbs & $174(54.4)$ \\
\hline Head, neck and face & $101(31.6)$ \\
\hline Thorax & $20(6.3)$ \\
\hline Other & $25(7.8)$ \\
\hline \multicolumn{2}{|l|}{ ED Disposition $(n=324)$} \\
\hline Discharged from ED & $218(67.3)$ \\
\hline Admitted & $65(20.1)$ \\
\hline Expired & $21(6.5)$ \\
\hline Others * & $20(6.2)$ \\
\hline
\end{tabular}

while the majority of those who died due to burns presented to private hospitals $(\mathrm{n}=16,76.2 \%)$ ( $\mathrm{p}$-value $<0.001)$.

Burns caused by scalds were the most common reason amongst those discharged from the ED $(n=153,70.2 \%)$, followed by fire, flame, or smoke $(n=29,13.3 \%)$. The common reasons amongst those admitted from the ED were scald $(n=36,55.4 \%)$. Fire, flame, or smoke was the most common cause of burns in patients who died in the $\operatorname{ED}(\mathrm{n}=17,81 \%)$. The extent of the burn injury was known for only a very small number of patients $(\mathrm{n}=26)$; a vast majority of those who were admitted suffered from $>20 \%$ burns $(n=6,85.7 \%)$. Information regarding degree of burns for patients who died was not available.

\section{Discussion}

This study presents data from seven major tertiary care centers in Pakistan, capturing important characteristics of burn injury patients. It is one of few studies to show the actual burden of burn injuries on the healthcare system. The majority of these patients used public transport to access the healthcare system. We show that males and young adults experience a higher proportion of burn injuries, but the majority of the mortality burden is borne by those older than 40 years. A high proportion of burn injury patients presenting to private hospitals died. Hot surfaces or liquid and burns due to 
Table 3. Comparison of characteristics of burn injury patients based on intent of injury $(n=308)$

\begin{tabular}{|c|c|c|c|c|c|}
\hline \multirow[t]{3}{*}{ Variables } & \multicolumn{4}{|c|}{ Intent of injury } & \multirow[t]{3}{*}{ p-value ${ }^{*}$} \\
\hline & \multicolumn{2}{|c|}{$\begin{array}{c}\text { Unintentional } \\
\mathrm{n}=201(65.2 \%)\end{array}$} & \multicolumn{2}{|c|}{$\begin{array}{c}\text { Intentional } \\
\mathrm{n}=107(34.7 \%)\end{array}$} & \\
\hline & $\mathrm{n}$ & $\%$ & $\mathrm{n}$ & $\%$ & \\
\hline Gender & & & & & 0.343 \\
\hline Male & 138 & 68.7 & 79 & 73.8 & \\
\hline Female & 63 & 31.3 & 28 & 26.2 & \\
\hline Age Group & & & & & $0.097^{* *}$ \\
\hline Under 5 years & 14 & 7 & 5 & 4.7 & \\
\hline 5-9 years & 15 & 7.5 & 3 & 2.8 & \\
\hline 10-19 years & 32 & 15.9 & 16 & 15 & \\
\hline 20-29 years & 67 & 33.3 & 37 & 34.6 & \\
\hline $30-39$ years & 26 & 12.9 & 25 & 23.4 & \\
\hline $40-49$ years & 32 & 15.9 & 10 & 9.3 & \\
\hline$\geq 50$ years & 15 & 7.5 & 11 & 10.3 & \\
\hline Mode of Transport $(n=269)$ & & & & & 0.135 \\
\hline Ambulance & 10 & 5.8 & 12 & 12.2 & \\
\hline Non ambulance & 161 & 94.1 & 86 & 87.8 & \\
\hline Hospital Type & & & & & $0.106^{* *}$ \\
\hline Public Hospital & 181 & 90 & 102 & 95.3 & \\
\hline Private Hospital & 20 & 10 & 5 & 4.7 & \\
\hline Cause Of Burn & & & & & $0.620^{* *}$ \\
\hline Scald & 135 & 67.2 & 64 & 59.8 & \\
\hline Fire/Flame/Smoke & 32 & 15.9 & 21 & 19.6 & \\
\hline Chemical & 5 & 2.5 & 4 & 3.7 & \\
\hline Others & 29 & 14.4 & 18 & 16.8 & \\
\hline \multicolumn{6}{|l|}{ Body part injured $(n=278)$} \\
\hline Limbs & 89 & 48.4 & 49 & 64.5 & \\
\hline Head, neck and face & 60 & 32.6 & 22 & 28.9 & $0.004^{* *}$ \\
\hline Thorax & 10 & 5.4 & 5 & 6.6 & \\
\hline Other & 25 & 13.6 & 0 & 0 & \\
\hline Degree Of Burn $(n=39)$ & & & & & $0.147^{* *}$ \\
\hline$>20 \%$ & 21 & 61.8 & 1 & 20 & \\
\hline$<20 \%$ & 13 & 38.2 & 4 & 80 & \\
\hline ED disposition $(n=252)$ & & & & & $0.025^{* *}$ \\
\hline Discharged from ED & 109 & 64.9 & 69 & 82.1 & \\
\hline Admitted from ED & 28 & 16.7 & 10 & 11.9 & \\
\hline Death & 17 & 10.1 & 3 & 3.6 & \\
\hline Others*** & 14 & 8.3 & 2 & 2.4 & \\
\hline
\end{tabular}

*p-value: bold values are significant. Analysis was conducted using Chi square test with level of significance 0.05

** Analysis was conducted using Fisher Exact test with level of significance 0.05

***Left without being seen, left against medical advice, referred patients

fire were the most common causes of burns, with death occurring more frequently among patients with firerelated burn injuries.

Our calculated incidence rate of 147 per 100,000 patients presenting to Pakistani EDs is almost twice that noted in a previous study conducted in Rawalpindi, Pakistan which reported an incidence of 76 per 100,000 for ED visits [20]. Our observations on gender differed from other studies from Pakistan, India, and Eastern
Mediterranean region, with fewer females as compared to males experiencing burn injuries $[11,14,21,22]$. The reason for fewer females presenting with burn injuries in our study may be due to under-reporting in females, delay in seeking care. For example, women might not seek care, or not be supported in seeking care, especially if the injury was intentional. This study shows a higher percentage of men presenting with intentional burn injuries. This is in contrast to a recent study from Nepal 
Table 4. Comparison of ED disposition of burn injury patients $(n=304)$

\begin{tabular}{|c|c|c|c|c|c|c|c|}
\hline \multirow[t]{3}{*}{ Variables } & \multicolumn{6}{|c|}{ ED disposition of burn injury patients } & \multirow[t]{3}{*}{ p-value* } \\
\hline & \multicolumn{2}{|c|}{$\begin{array}{c}\text { Discharged from ED } \\
n=218\end{array}$} & \multicolumn{2}{|c|}{$\begin{array}{c}\text { Admitted } \\
n=65\end{array}$} & \multicolumn{2}{|c|}{$\begin{array}{l}\text { Death } \\
n=21\end{array}$} & \\
\hline & $n$ & $\%$ & $\mathrm{n}$ & $\%$ & $\mathrm{n}$ & $\%$ & \\
\hline Gender & & & & & & & 0.019 \\
\hline Male & 152 & 69.7 & 38 & 58.5 & 19 & 90.5 & \\
\hline Female & 66 & 30.3 & 27 & 41.5 & 2 & 9.5 & \\
\hline Age Group & & & & & & & $<0.001$ \\
\hline Under 5 years & 11 & 5 & 5 & 7.7 & -0 & 0 & \\
\hline $5-9$ years & 11 & 5 & 3 & 4.6 & 0 & 0 & \\
\hline 10-19 years & 39 & 17.9 & 10 & 15.4 & 2 & 9.5 & \\
\hline $20-29$ years & 80 & 36.7 & 20 & 30.8 & 3 & 14.3 & \\
\hline 30-39 years & 32 & 14.7 & 14 & 21.5 & 3 & 14.3 & \\
\hline $40-49$ years & 27 & 12.4 & 7 & 10.8 & 13 & 61.9 & \\
\hline$\geq 50$ years & 18 & 8.3 & 6 & 9.2 & 0 & 0 & \\
\hline Mode of Transport $(n=270)$ & & & & & & & 0.04 \\
\hline Ambulance & 11 & 5.3 & 7 & 11.7 & 1 & 33.3 & \\
\hline Non ambulance & 196 & 94.7 & 53 & 88.3 & 2 & 66.6 & \\
\hline Hospital Type & & & & & & & $<0.001$ \\
\hline Public Hospital & 212 & 97.2 & 63 & 96.9 & 5 & 23.8 & \\
\hline Private Hospital & 6 & 2.8 & 2 & 3.1 & 16 & 76.2 & \\
\hline Intentional Type & & & & & & & 0.186 \\
\hline Self-inflicted & 33 & 18.5 & 4 & 10.5 & 1 & 5 & \\
\hline Assault & 36 & 20.2 & 6 & 15.8 & 2 & 10 & \\
\hline Unintentional & 109 & 61.2 & 28 & 73.7 & 17 & 85 & \\
\hline Cause Of Burn & & & & & & & $<0.001$ \\
\hline Scalds & 153 & 70.2 & 36 & 55.4 & 1 & 4.8 & \\
\hline Fire/Flame/Smoke & 29 & 13.3 & 8 & 12.3 & 17 & 81 & \\
\hline Chemical & 6 & 2.8 & 1 & 1.5 & 1 & 4.8 & \\
\hline Others & 30 & 13.8 & 20 & 30.8 & 2 & 9.5 & \\
\hline Body part injured $(n=252)$ & & & & & & & $<0.001$ \\
\hline Limbs & 113 & 63.1 & 26 & 48.1 & 0 & 0 & \\
\hline Head, neck and face & 53 & 29.6 & 22 & 40.7 & 1 & 5.3 & \\
\hline Thorax & 11 & 6.1 & 6 & 11.1 & 1 & 5.3 & \\
\hline Other & 2 & 1.1 & 0 & 0 & 17 & 89.5 & \\
\hline Degree Of Burn $(n=26)$ & & & & & & & 0.073 \\
\hline$>20 \%$ & 7 & 36.8 & 6 & 85.7 & 0 & 0 & \\
\hline$<20 \%$ & 12 & 63.2 & 1 & 14.3 & 0 & 0 & \\
\hline
\end{tabular}

*p-value: bold values are significant.

Analysis was conducted using Fisher Exact test with level of significance 0.05

which reported more females presenting with intentional burn injury [23]. Our findings also differ from various facility-based studies from India and China $[22,24]$ and population-based reviews from the Eastern Mediterranean and South-East Asia regions of WHO [21,25], where males under 5 years and adolescent and young females were reported to experience more burn injuries.

Similar to this study, a higher incidence of burn injuries among young adults has been reported at the country and regional level in other studies from China, Pakistan, India, Iran, and Turkey [15,21,22,24-27].
However, other studies from Bangladesh and Oman have identified children and elderly as the most vulnerable groups, which is in contrast to this study's findings $[7,28,29]$. Injuries in young adults have economic implications for both the affected individuals and their families, given high levels of participation in the workforce at these ages, necessitating an accurate assessment.

In our study, those who died had suffered from firerelated burns and were more likely to be older individuals. Burn-related injuries are the fourth leading cause of unintentional injury death in the elderly and this risk is 
disproportionately higher for this age group compared to the general population [6]. Our study showed overall burn mortality to be $6.5 \%$, which is lower compared to other studies performed in Pakistan, which have reported mortality due to burn injuries ranging from $14 \%-41.3 \%$ [11-15]. A possible reason for this discrepancy could be the fact that several of these earlier studies were conducted in specialized burn centers and units and/or that there may be under-reporting of deaths in Pak-NEDS. The mortality due to burn injuries among various countries in the WHO Eastern Mediterranean Region varies between 5\% - 37\% [21]. This variation in mortality could be because of different study settings, burn severity, availability of experts, or resources to manage burns. Although previous studies on burns have shown that there is higher mortality among patients with intentional burn injuries, our study showed that the majority of such patients were discharged from the ED [23]. This could be because most of the patients with intentional burn injuries are taken to specialized burn centers due to the severity of their injuries.

Scald and flame burns were the most common cause of burns, which is consistent with previous studies from Pakistan, Iran, India, and reviews from the EMRO region $[11,13,14,21,22,25,27,30]$. Our study lacks information related to the cause of the fire or flame; however, previous studies have reported kerosene stove burners and wood-based cooking fuel as the main source of burn related injuries amongst females of Southeast Asia [22].

Most of the existing centers are located in major cities of the country. Karachi, the largest metropolis in the country with more than 20 million people, has just one public and one private sector burn center [11,31]. More rural areas of the country face an even worse situation, with few centers equipped to handle burn injuries and limited options for referral. These facilities, most often in the public sector, are typically preferred by patients, as they are economical or free of cost, and more easily accessible. However, they tend to lack basic necessities such as equipment and trained healthcare providers.

Our analysis demonstrated that most of the deaths by burn injury occurred in private hospitals, perhaps as a result of more severe burns being treated there compared to those who went to public hospitals. Another possible cause could be that these patients may have been referred to private hospitals from public hospitals for further management [15]. There are also other factors that may influence the lack of care for patients with burn injuries in Pakistan including: densely populated areas; the vast catchment area for each tertiary care hospital (public and private); poor economic and educational status of the population; lack of awareness regarding prevention practices, such as safe fire use; or use of non-approved and inappropriate first aid treatments like applying tooth paste, cow dung, or other home remedies [32,33].

This study was one of the largest multi-center collaboration of EDs in Pakistan; the hospitals represented only major tertiary care hospitals in large cities across the country. This study therefore might not have captured patients who do not typically present at these types of hospitals, such as those that might have utilized primary or secondary centers, or those who might have the participating hospitals might have also resulted in a skewed distribution of demographic characteristics of patients, burn injury, and outcome. This study lacked information related to location of burn injury such as home or workplace; causes of burn such as kerosene oil, electricity, or chemicals; severity of burn injury including total body surface area burnt; and associated injuries and comorbid conditions. These are important factors to consider to determine outcomes of burn injury patients [21].

The dataset had missing information for some variables such as $23.6 \%$ for intent of injury, $20.6 \%$ for body part injured, and $19.6 \%$ for ED disposition. This resulted in limitations in performing regression analysis to get an in-depth understanding of risk factors associated with the burns presenting to EDs in Pakistan. This highlights the need for better data records in the EDs of Pakistan.

\section{Conclusion}

We were able to demonstrate a significant burden of burn injuries that is not addressed by specialized burn centers. There is also a critical need to continue research and surveillance on burn patients in Pakistan, in order to broaden the evidence base on the epidemiology of these injuries, as well as the outcomes of patients following discharge. Such information, if available in future studies, will inform programs and policy emphasizing primary prevention, short-term treatment, and long-term management of burn injuries in low-resource settings such as Pakistan where these efforts are extremely deficient.

\section{Competing interests}

The authors declare that they have no competing interests.

\section{Authors' contributions}

EMS developed the initial draft. NZ was involved in data analysis and interpretation, draft writing and revision of the manuscript. AF and SA were involved in data management and analysis. ALA helped with the writing of the draft. AL was involved with data analysis and interpretation, and critical revision of the manuscript. JAR and AAH were involved in design of PakNEDS, and had overseen overall data analysis and interpretation and review of the paper. All authors approved of the final draft.

\section{Acknowledgements}

The authors would like to thank the data collection team at each participating site. We are also grateful to Ms. Leann Rosenberg for language 
editing of the paper. The Pak-NEDS study was supported through the "Johns Hopkins International Collaborative Trauma and Injury Research Training Program" [Grant No. D43TW007292] by Fogarty International Center of the United States National Institutes of Health. The content is solely the responsibility of the authors and does not represent the views of Fogarty or $\mathrm{NIH}$.

This article has been published as part of BMC Emergency Medicine Volume 15 Supplement 2, 2015: Articles from the Pakistan National Emergency Departments Surveillance Study (Pak-NEDS). The full contents of the supplement are available online at http://www.biomedcentral.com/ bmcemergmed/supplements/15/S2. Publication of this supplement was funded by the Johns Hopkins School of Public Health.

\section{Authors' details}

'Department of Emergency Medicine, Aga Khan University, Karachi, Pakistan. ${ }^{2}$ Department of Medicine, Aga Khan University, Karachi, Pakistan.

${ }^{3}$ Department of Emergency Medicine, John Hopkins School of Medicine, Baltimore, MD, USA. ${ }^{4}$ Johns Hopkins International Injury Research Unit, Department of International Health, Johns Hopkins Bloomberg School of Public Health, Baltimore, MD, USA. ${ }^{5}$ Department of Anesthesiology and Critical Care Medicine, Johns Hopkins University School of Medicine, Baltimore, MD, USA. ${ }^{6}$ The author was affiliated with the Department of Emergency Medicine, Aga Khan University, Karachi, Pakistan at the time when study was conducted.

Published: 11 December 2015

\section{References}

1. Peck M, Molnar J, Swart D: A global plan for burn prevention and care. Bulletin of the World Health Organization 2009, 87(10):802-803.

2. Global Burden of Disease. The Institute for Health Metrics and Evaluation. [http://www.healthdata.org/gbd].

3. Global Burden of Disease. The Institute for Health Metrics and Evaluation. Geneva: World Health Organization; 2008.

4. Olaitan PB, Olaitan JO: Burns and scalds-epidemiology and prevention in a developing country. Niger J Med 2004, 14(1):9-16.

5. Peck MD: Epidemiology of burns throughout the world. Part I: Distribution and risk factors. Burns 2011, 37(7):1087-1100.

6. WHO Burns fact sheet. [http://www.who.int/mediacentre/factsheets/fs365/ en/].

7. Forjuoh SN: Burns in low- and middle-income countries: a review of available literature on descriptive epidemiology, risk factors, treatment, and prevention. Burns: journal of the International Society for Burn Injuries 2006, 32(5):529-537.

8. WHO Department of Measurement and Health Information. Death and DALY estimates for 2004 by cause for WHO member states. Geneva, Switzerland: World Health Organization; 2009.

9. Annual incidence (000s) for selected causes, in WHO Regions, Regional estimates for 2000 - 2011. [http://www.who.int/healthinfo/ global_burden_disease/estimates_regional/en/index.html].

10. Marsh D, Sheikh A, Khalil A, Kamil S, Jaffer uz Z, Qureshi I, Siraj Y, Luby S, Effendi S: Epidemiology of adults hospitalized with burns in Karachi, Pakistan. Burns 1996, 22(3):225-229.

11. Hashmi M, Kamal R: Management of patients in a dedicated burns intensive care unit (BICU) in a developing country. Burns 2013, 39(3):493-500.

12. Khaliq MF, Noorani MM, Siddiqui UA, Al Ibran E, Rao MH: Factors associated with duration of hospitalization and outcome in burns patients: A cross sectional study from Government Tertiary Care Hospital in Karachi, Pakistan. Burns 2013, 39(1):150-154.

13. Al Ibran E, Mirza FH, Memon AA, Farooq MZ, Hassan M: Mortality associated with burn injury-A cross sectional study from Karachi, Pakistan. BMC Research Notes 2013, 6(1):545.

14. Iqbal T, Saaiq M, Ali Z: Epidemiology and outcome of burns: Early experience at the country's first national burns Centre. Burns 2013, 39(2):358-362.

15. Khan N, Malik MAN: Presentation of burn injuries and their management outcome. Journal of Pakistan Medical Association 2006, 56(9):394-397.

16. Emergency Department Patient Record Form. National Hospital Ambulatory Medical Care Survey
17. Razzak JA, Shamim MS, Mehmood A, Hussain SA, Ali MS, Jooma R: A successful model of Road Traffic Injury surveillance in a developing country: process and lessons learnt. BMC public health 2012, 12:357.

18. CDC. Epi Info 3.3.2. Atlanta, GA: Centers for Disease Control and Prevention; 2005.

19. IBM Corp. IBM SPSS Statistics for Windows Version 20.0. Armonk, NY IBM Corp; 2011.

20. Farooq U, Nasrullah M, Bhatti JA, Majeed M, Hanif M, Khan JS, Khan MM: Incidence of burns and factors associated with their hospitalisation in Rawalpindi, Pakistan. Burns 2011, 37(3):535-540.

21. Othman N, Kendrick D: Epidemiology of burn injuries in the East Mediterranean Region: a systematic review. BMC public health 2010, 10:83.

22. Kumar S, Ali W, Verma AK, Pandey A, Rathore S: Epidemiology and mortality of burns in the Lucknow Region, India-a 5 year study. Burns 2013, 39(8):1599-1605.

23. Lama BB, Duke JM, Sharma NP, Thapa B, Dahal P, Bariya ND, Marston W, Wallace HJ: Intentional burns in Nepal: A comparative study. Burns 2015, 41(6)

24. Tang K, Jian L, Qin Z, Zhenjiang L, Gomez M, Beveridge M: Characteristics of burn patients at a major burn center in Shanghai. Burns: journal of the International Society for Burn Injuries 2006, 32(8):1037-1043.

25. Golshan A, Patel C, Hyder AA: A systematic review of the epidemiology of unintentional burn injuries in South Asia. Journal of public health 2013, 35(3):384-396.

26. Coruh A, Gunay GK, Esmaoglu A: A seven-year burn unit experience in Kayseri, Turkey: 1996 to 2002. Journal of Burn Care \& Research 2005, 26(1):79-84.

27. Sadeghi-Bazargani $H$, Mohammadi R: Epidemiology of burns in Iran during the last decade (2000-2010): review of literature and methodological considerations. Burns 2012, 38(3):319-329.

28. Mashreky SR, Rahman A, Chowdhury SM, Khan TF, Svanstrom L, Rahman F: Non-fatal burn is a major cause of illness: findings from the largest community-based national survey in Bangladesh. Inj Prev 15(6):397-402.

29. Thomas C, Prasanna M: The role of a 'satellite-service' in the national organisation of burn care in the Sultanate of Oman. Burns 2000, 26(2):181-185.

30. Bain J, Lal S, Baghel VS, Yedalwar V, Gupta R, Singh AK: Decadorial of a burn center in Central India. Journal of natural science, biology, and medicine 2014, 5(1):116-122.

31. Friends of Burn Centre. [http://www.burnscentre.org/]

32. Peden MM: World report on child injury prevention. World Health Organization; 2008.

33. Shanmugakrishnan RR, Narayanan $V$, Thirumalaikolundusubramanian $P$ : Epidemiology of burns in a teaching hospital in south India. Indian J Plast Surg 2008, 41(1):34-37.

doi:10.1186/1471-227X-15-S2-S5

Cite this article as: Siddiqui et al.: Burn injury characteristics: findings from Pakistan National Emergency Department Surveillance Study. BMC Emergency Medicine 2015 15(Suppl 2):S5.

\section{Submit your next manuscript to BioMed Central and take full advantage of:}

- Convenient online submission

- Thorough peer review

- No space constraints or color figure charges

- Immediate publication on acceptance

- Inclusion in PubMed, CAS, Scopus and Google Scholar

- Research which is freely available for redistribution 